\title{
MANEJO DA IRRIGAÇÃO (TENSIOMETRIA E BALANÇO HÍDRICO CLIMATOLÓGICO) PARA A CULTURA DO FEIJOEIRO EM SISTEMAS DE CULTIVO DIRETO E CONVENCIONAL ${ }^{1}$
}

\author{
ADRIANO S. LOPES ${ }^{2}$, LUIZ C. PAVANI ${ }^{3}$, JOSÉ E. CORÁ ${ }^{4}$, JOSÉ R. ZANINI ${ }^{3}$, \\ HECTOR A. MIRANDA ${ }^{5}$
}

\begin{abstract}
RESUMO: Dois métodos de manejo de irrigação, por tensiometria e pelo balanço hídrico climatológico simplificado baseado no tanque "Classe A", foram aplicados e avaliados os resultados no balanço de água no solo, na evapotranspiração e na produtividade de grãos da cultura do feijoeiro, cultivar IAC-Carioca, conduzida na estação seca com irrigação por pivô central, após uma cultura de milho (estação úmida), no primeiro ano de cultivo, nos sistemas de plantio direto e convencional em uma área de Latossolo Vermelho. Concluiu-se que ambos os métodos são possíveis de serem adotados por irrigantes ou técnicos com níveis médios de tecnologia e conhecimento, embora com a tensiometria seja possível um melhor entendimento das reais condições hídricas do solo na região do sistema radicular da cultura. Não foram verificadas diferenças importantes de armazenamento de água no solo e de produtividade de grãos entre os sistemas de plantio nesse primeiro ano; o manejo por tensiometria resultou em maiores variações na água disponível consumida do que o do balanço hídrico climatológico simplificado e resultou, em relação a esse, economia de $15 \%$ na água de irrigação aplicada, sem afetar a produtividade de grãos.
\end{abstract}

PALAVRAS-CHAVE: água no solo, evapotranspiração, pivô central.

\section{IRRIGATION MANAGEMENT (TENSIOMETRY AND SIMPLIFIED CLIMATOLOGICAL WATER BALANCE) IN IRRIGATED BEAN UNDER CONVENTIONAL AND NO TILLAGE SYSTEMS}

SUMMARY: Two methods of irrigation management, tensiometry and simplified climatological water balance with Class A pan, were applied in a bean crop, IAC-Carioca cultivar, growing in a Oxisol, irrigated by center pivot under conventional and no tillage systems. The soil water balance, evapotranspiration and bean yield were evaluated. The results showed that, both irrigation management methods are possible to be adopted for farmers or technicians with average level of technology and knowledge. However, the tensiometry offers a better understanding of the real soil water conditions at plant root system. Differences of soil water storage and grain yield between tillage systems were not verified. The tensiometry management method resulted in a higher variations of plant available water when compared to the simplified climatological water balance. The tensiometry management method made possible reduction of $15 \%$ of the irrigation water, when compared to the simplified water balance, without affecting the grain yield.

KEYWORDS: soil water, evapotranspiration, center pivot.

\footnotetext{
${ }^{1}$ Parte da Dissertação do primeiro autor.

2 Professor Assistente, Universidade Estadual de Mato Grosso do Sul, Unidade de Aquidauana, Doutorando em Produção Vegetal , FCAV/UNESP, Fone: (0XX67) 241.4250, e-mail: lopes@uems.br.

${ }^{3}$ Prof. Dr., Departamento de Engenharia Rural, FCAV/UNESP, Jaboticabal - SP.

${ }^{4}$ Prof. Dr., Departamento de Solos e Adubos, FCAV/UNESP, Jaboticabal - SP.

${ }^{5}$ Prof. Msc., Universidad Centroccidental "Lisandro Alvarado" Decanato de Agronomia, Barquisimeto - Lara - Venezuela.

Recebido pelo Conselho Editorial em: 9-5-2003

Aprovado pelo Conselho Editorial em: 11-2-2004
} 


\section{INTRODUÇÃO}

A adoção de técnicas racionais de manejo conservacionista do solo e da água é de fundamental importância para a sustentabilidade, de tal forma que se possa, economicamente, manter ao longo do tempo esses recursos com quantidade e qualidade suficientes para a manutenção de níveis satisfatórios de produtividade (WUTKE et al., 2000).

Em regiões em que, durante uma parte do ano, as condições de temperatura e de radiação solar são suficientes para a produção agrícola, mas existe um déficit hídrico importante, como nas regiões norte, nordeste e noroeste do Estado de São Paulo, a adoção de técnicas conjugadas de plantio direto e de irrigação tem se mostrado promissora, sob o ponto de vista de melhor explorar a terra e também sob o aspecto conservacionista, uma vez que, segundo STONE \& MOREIRA (2000; 2001), o plantio direto com adequada cobertura morta propicia maior economia de água em comparação com os demais sistemas de preparo do solo e, no decorrer dos anos, melhoria nas características físicas do solo.

$\mathrm{O}$ conhecimento da quantidade de água requerida pelas culturas constitui-se em aspecto importante na agricultura irrigada para que haja uma adequada programação de manejo de irrigação. Segundo HERNANDEZ (1994), existem várias metodologias e critérios para estabelecer programas de irrigação, que vão desde simples turnos de rega a completos esquemas de integração do sistema soloágua-planta-atmosfera. Entretanto, reconhece-se que, ao agricultor, devem ser fornecidas técnicas simples, mas com precisão suficiente para possibilitarem, no campo, a determinação criteriosa do momento e da quantidade de água a ser aplicada.

Para PEREIRA \& ALLEN (1997), a medida direta da evapotranspiração é extremamente difícil e onerosa. Difícil, porque exige instalações e equipamentos especiais e, onerosa, porque tais estruturas são de alto custo, justificando-se apenas em condições experimentais. Entretanto, de acordo com OLIVEIRA \& SILVA (1990), a identificação da evapotranspiração real (ETr) contribui para melhor eficiência no manejo da água de irrigação e, conseqüentemente, evita que se coloque à disposição da cultura água em excesso ou em déficit.

O objetivo deste trabalho foi aplicar dois métodos de manejo de irrigação, por tensiometria e pelo balanço hídrico simplificado baseado na diferença entre a evapotranspiração estimada pelo método do tanque "Classe A" e a chuva, e avaliar o resultado da aplicação desses dois métodos no balanço de água no solo, no consumo de água pelas plantas e na produtividade de grãos da cultura do feijoeiro conduzida após uma cultura de milho (estação úmida), em sistemas de plantio direto e convencional.

\section{MATERIAL E MÉTODOS}

O experimento foi instalado em área com declividade média de $8 \%$, no município de Jaboticabal - SP, com coordenadas geográficas de $21^{\circ} 15^{\prime}$ Sul, $48^{\circ} 18^{\prime}$ Oeste e altitude média de $575 \mathrm{~m}$. As normais climatológicas do município, como valores médios anuais do período de 1971 a 2000 são: 1.424,6 mm de chuva; $943,5 \mathrm{hPa}$ de pressão atmosférica; $28,9{ }^{\circ} \mathrm{C}, 16,8{ }^{\circ} \mathrm{C}$ e $22,2{ }^{\circ} \mathrm{C}$ de temperaturas máximas, mínima e média do ar, respectivamente; $70,8 \%$ de umidade relativa do ar; insolação total de $2.585,8 \mathrm{~h}$ e um total de 117,5 dias com chuva ${ }^{1}$. O solo da área foi classificado como Latossolo Vermelho Eutroférrico, segundo recomendações da EMBRAPA (1999).

\section{Sistema de irrigação, delineamento experimental e tratamentos empregados}

O experimento foi conduzido em uma área irrigada de 3,3 ha, com um sistema pivô central, cujas uniformidade de aplicação de água e as lâminas médias aplicadas, em diversas velocidades de rotação, foram avaliadas antes da instalação das parcelas experimentais.

\footnotetext{
${ }^{1}$ Dados obtidos em: www.fcav.unesp.br/departamentos/exatas/estacao/normal.html, acesso em 30 de março de 2003.
} 
O delineamento experimental utilizado foi semelhante ao de blocos casualizados, em um esquema fatorial $2 \times 2$, composto por três blocos, com três parcelas em cada um (PIMENTEL GOMES, 1963), conforme esquema da Figura 1. Os resultados de produtividade de grãos e lâmina total de água recebida pela cultura foram analisados por meio do teste de Tukey $(\mathrm{P}<0,05)$.

Os tratamentos foram dois métodos de manejo de irrigação e dois sistemas de cultivo assim descritos: manejo da irrigação por tensiometria (TENS) e pelo balanço hídrico climatológico simplificado baseado no método do tanque "Classe A" (TCA); sistemas convencional (PC), em que se realizaram duas gradagens pesadas e uma para o destorroamento e incorporação de herbicida préplantio (trifluralina), e plantio direto (PD), em que foi aplicado herbicida dessecante antes da semeadura.

\section{Instalação e condução da cultura}

Na área sob o pivô central foi realizada a semeadura do milho (Zea mays L.) em 24-10-2001, cuja colheita foi realizada em 3-4-2002. Após a colheita do milho e preparo do solo na área sob cultivo convencional e aplicação de herbicida glifosato $\left(6,0 \mathrm{~L} \mathrm{ha}^{-1}\right)$ no plantio direto, realizou-se a semeadura do feijoeiro (Phaseolus vulgaris L.) cultivar IAC-Carioca, a qual ocorreu em 8-6-2002. A adubação de plantio constituiu de $214 \mathrm{~kg} \mathrm{ha}^{-1}$ de adubo da formulação 10-20-20, baseada na análise química do solo, e a adubação de cobertura foi realizada aos 15 dias após a emergência (DAE), utilizando-se de nitrato de amônio $\left(70 \mathrm{~kg} \mathrm{ha}^{-1}\right.$, de N). Foram aplicados inseticidas para o controle preventivo da moscabranca (Bemisia tabaci), para o controle da mosca-minadora (Liriomyza sp.), lagarta-elasmo (Elasmopalpus lignosellus) e vaquinha (Diabrotica speciosa). Também foi aplicado, aos 25 DAE, herbicida seletivo para a cultura do feijoeiro.

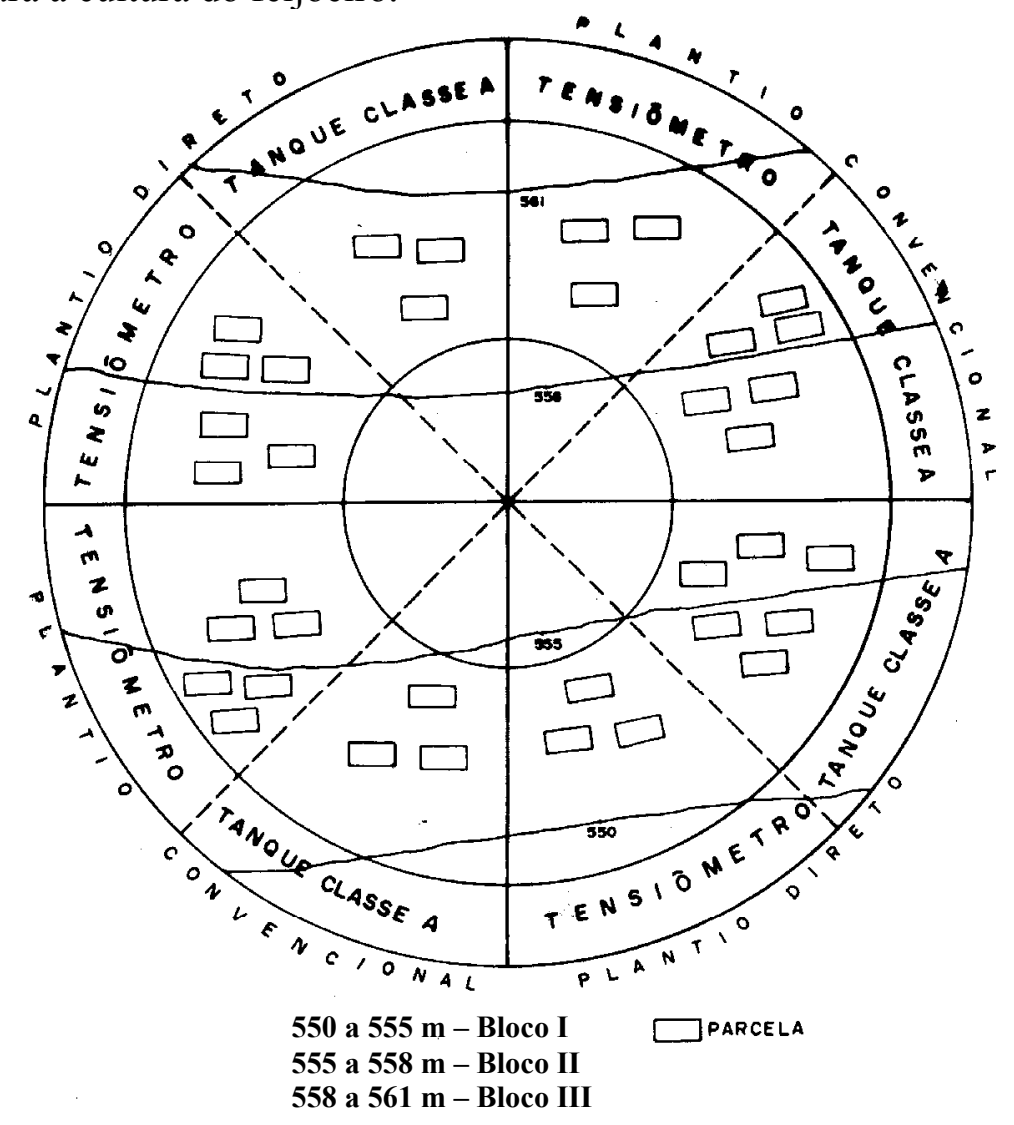

FIGURA 1. Esquema geral da área experimental, em que cada bloco equivale à cota correspondente, sem escala. 


\section{Manejo da irrigação}

A curva característica de retenção de água no solo foi determinada para o perfil de 0 a $0,40 \mathrm{~m}$ de profundidade, considerada essa a profundidade efetiva do sistema radicular da cultura (OLIVEIRA \& SILVA, 1990; PIRES et al., 1991; LIBARDI \& SAAD, 1994; WUTKE et al., 2000; PIRES et al., 2001). Foram também determinadas a capacidade de água disponível no solo (CAD, em mm), a água facilmente disponível no solo (AFD, em $\mathrm{mm}$ ) e a reserva de água disponível crítica do solo (RADc, em $\mathrm{mm}$ ), de acordo com as expressões:

$$
\begin{aligned}
& \mathrm{CAD}=(\theta \mathrm{cc}-\theta \mathrm{pmp}) 1000 \mathrm{Z} \\
& \mathrm{AFD}=(\theta \mathrm{cc}-\theta \mathrm{c}) 1000 \mathrm{Z} \\
& \mathrm{RADc}=\mathrm{CAD}-\mathrm{AFD}
\end{aligned}
$$

em que,

$\theta \mathrm{cc}$ - umidade do solo à capacidade de campo para o potencial mátrico de $-10 \mathrm{kPa}, \mathrm{m}^{3} \mathrm{~m}^{-3}$;

$\theta \mathrm{c}$ - umidade crítica do solo para a cultura do feijoeiro, cujo valor do potencial mátrico crítico ( $\Psi \mathrm{c})$ é de $-40 \mathrm{kPa}$ (SILVEIRA \& STONE, 1994), $\mathrm{m}^{3} \mathrm{~m}^{-3}$;

Өpmp - umidade do solo no ponto de murchamento permanente para o potencial mátrico de $-1500 \mathrm{kPa}, \mathrm{m}^{3} \mathrm{~m}^{-3}$, e

$\mathrm{Z}$ - profundidade, $0,40 \mathrm{~m}$.

Também foi determinada a água disponível consumida do solo até o dia da irrigação (ADCi), para TENS e TCA.

O dia definido como o de irrigação, tanto para TENS quanto para TCA, foi aquele em que a umidade atual do solo ( $\theta$ a) atingiu valor igual ou menor ao de $\theta \mathrm{c}$, considerando também se, no dia previsto ou nos três dias posteriores, a probabilidade de ocorrência de chuva igual ou maior do que a AFD fosse maior ou igual a $70 \%$. Se isso acontecesse, verificava-se se esse evento se confirmava no dia, e com qual quantidade. Caso contrário, acompanhava-se a previsão do dia seguinte e dos dois dias posteriores a esse, se necessário. Não se confirmando nesses a ocorrência de chuva, procedia-se à irrigação com a lâmina correspondente à água disponível consumida do solo até o dia da irrigação $\left(\mathrm{ADC}_{\mathrm{i}}\right)$.

Os dados utilizados de previsão de chuva para Jaboticabal - SP, foram obtidos diariamente pela manhã, por correio eletrônico (ctmail@climatempo.net ou www.climatempo.com.br).

\section{Tensiometria}

Nas parcelas em que o manejo da irrigação foi efetuado com tensiômetros, os mesmos foram instalados a $0,15 \mathrm{~m}$ e a $0,30 \mathrm{~m}$ de profundidade (SILVEIRA \& STONE, 1994), sendo o de $0,15 \mathrm{~m}$ o de decisão do momento de irrigar, enquanto o de $0,30 \mathrm{~m}$ o de controle da profundidade da lâmina aplicada (SAAD \& LIBARDI, 1992).

O momento de irrigar foi definido para cada um dos sistemas de cultivo (PC e PD) quando a média entre as leituras dos tensiômetros de decisão, em cada sistema, foi próxima ao valor crítico de potencial mátrico de água no solo $(\Psi \mathrm{c})$. A lâmina de irrigação ou água disponível consumida até o dia da irrigação $\left(\mathrm{ADCi}_{(\mathrm{Tens})}\right)$, em mm, foi calculada conforme a expressão:

$$
\mathrm{ADCi}_{(\text {Tens })}=(\theta \mathrm{cc}-\theta \mathrm{ai}) 1000 \mathrm{Z}
$$

em que,

Өai - umidade atual do solo no momento da irrigação, $\mathrm{m}^{3} \mathrm{~m}^{-3}$. 
A lâmina real $(h r$, em mm) aplicada em cada irrigação foi baseada na lâmina média obtida da avaliação do equipamento e na leitura dos pluviômetros instalados no experimento logo após as irrigações.

\section{Tanque "Classe A"}

O manejo da irrigação pelo balanço hídrico climatológico simplificado considerou apenas o balanço em 24 horas entre a evapotranspiração da cultura (ETc), estimada pelo método do tanque "Classe A", segundo ALLEN et al. (1998a e b), e a chuva total coletada em um pluviômetro tipo "Ville de Paris". Não foi considerada a chuva efetiva no lugar da chuva total por ser de difícil determinação ou estimativa para o agricultor irrigante e mesmo para um técnico com acesso a um nível médio de tecnologia e conhecimento do assunto. Assim, o cálculo da lâmina líquida real ou $\mathrm{ADCi}_{(T C A)}$, tomada como referência para a lâmina de irrigação a ser aplicada com o pivô central, foi obtido da seguinte expressão do balanço hídrico climatológico simplificado:

$$
\mathrm{ADCi}_{(\mathrm{TCA})}=\sum_{\mathrm{ti}}^{\mathrm{tj}}(\mathrm{ETc}-\mathrm{P})
$$

em que,

$\mathrm{ADCi}_{(\mathrm{TCA})} \geq \mathrm{AFD}, 18,6 \mathrm{~mm}, \mathrm{e}$

(tj-ti) - duração do intervalo, em dias, entre duas irrigações.

A ETc (mm dia $\left.{ }^{-1}\right)$ foi estimada de acordo com a expressão:

$\mathrm{ETc}=\mathrm{ECA} \mathrm{Kp} \mathrm{Kc}$

em que,

ECA - evaporação medida no tanque "Classe A" $\left(\mathrm{mm} \mathrm{dia}^{-1}\right)$;

$\mathrm{Kp}$ - coeficiente de tanque (adimensional) cujas determinações foram baseadas em ALLEN et al. (1998a), e

Kc - coeficiente de cultura simplificado (adimensional), estimado diariamente para a cultura do feijoeiro, de acordo com ALLEN et al. (1998b).

\section{Parâmetros avaliados}

\section{Variação da umidade do solo}

Foi avaliada indiretamente por meio dos valores de potencial mátrico obtidos dos tensiômetros instalados a 0,$10 ; 0,30 ; 0,50$ e $0,70 \mathrm{~m}$ de profundidade nas parcelas destinadas à estimativa do balanço hídrico do solo e a 0,15 e $0,30 \mathrm{~m}$ nas parcelas destinadas ao manejo da irrigação. Esse valores foram transformados em umidade volumétrica, utilizando-se da equação de GENUCHTEN (1980).

Para verificar a possível ocorrência de déficit hídrico no solo em relação à planta, foi calculada, diariamente, a reserva de água disponível atual no solo até a profundidade de 0,40 $\mathrm{m}$ (RADa, $\mathrm{mm}$ ) para todos os tratamentos, por meio da expressão:

$$
\mathrm{RADa}=\mathrm{CAD}-\mathrm{ADCa}
$$

sendo, $\mathrm{ADCa}$ a água disponível consumida atual do solo $(\mathrm{mm})$, que foi calculada por:

$$
\mathrm{ADCa}=(\theta \mathrm{cc}-\theta \mathrm{a}) 1000 \mathrm{Z}
$$

sendo, $\theta$ a umidade média atual do solo na camada de $0,40 \mathrm{~m}, \mathrm{Z}$.

Para comparação, foi tomada como referência a RAD limite (RADl) calculada pela expressão:

$$
\mathrm{RADl}=(1-\mathrm{p}) \mathrm{CAD}
$$


sendo $\mathrm{p}$ o fator de depleção de água no solo calculado diariamente em função da ETc diária estimada pelo método do tanque "Classe A", utilizando-se da expressão apresentada por ALLEN et al. (1998c).

Como a RADl é uma fração da CAD, a RADa foi também assim transformada, sendo reapresentada pela expressão:

$$
\mathrm{RADa}=1-\frac{\mathrm{ADCa}}{\mathrm{CAD}}
$$

\section{Estimativa da ETr pelo método do balanço hídrico do solo}

Foram instalados dois ensaios logo após a colheita do feijoeiro, para a determinação da condutividade hidráulica do solo, sendo um na área de PC e outro na área de PD, cada um com $4 \mathrm{~m}^{2}$ de área, na qual foram instalados quatro tensiômetros às profundidades de 0,$10 ; 0,30 ; 0,50$ e $0,70 \mathrm{~m}$. A condutividade hidráulica do solo $\left(\mathrm{K}(\theta), \mathrm{m} \mathrm{h}^{-1}\right)$ a $0,40 \mathrm{~m}$ de profundidade foi determinada pelo método do perfil instantâneo, seguindo metodologia proposta por LIBARDI (1995). O modelo aplicado foi:

$$
\mathrm{K}(\theta)=\mathrm{K}_{0} \exp ^{\left[\gamma\left(\theta_{\mathrm{a}}-\theta_{0}\right)\right]}
$$

em que,

$\mathrm{K}_{0}$ - condutividade hidráulica do solo saturado;

exp - base do logaritmo neperiano;

$\gamma$ - inverso do coeficiente angular, e

$\theta_{\mathrm{o}}$ - umidade volumétrica do solo saturado.

A evapotranspiração real média (ETr) de um período de $n$ dias foi estimada de acordo com a expressão do balanço hídrico completo do solo:

$$
\mathrm{ETr}=\frac{1}{\mathrm{n}} \sum_{\mathrm{i}=1}^{\mathrm{n}}\left(\mathrm{P}+\mathrm{I}-\Delta \mathrm{A}_{\mathrm{Z}}-\mathrm{ES} \pm \mathrm{q}\right)_{\mathrm{i}}
$$

em que,

$\mathrm{P}$ - chuva diária, mm;

I - lâmina real de irrigação coletada em pluviômetros instalados nas parcelas a $0,50 \mathrm{~m}$ de altura, $\mathrm{mm}$;

$\Delta \mathrm{A}_{\mathrm{Z}}$ - variação do armazenamento de água no perfil de solo considerado, mm;

ES - escoamento superficial produzido na área, mm, e

$\mathrm{q}$ - drenagem profunda (-) ou a ascensão capilar (+), em $\mathrm{mm} \mathrm{dia}^{-1}$.

A ETr foi estimada para $n$ igual a sete dias, entre 17 e 86 DAE das plântulas e para dez dias no período final (87 a $96 \mathrm{DAE}$ ). Também foi obtida para três fases fenológicas distintas: desenvolvimento vegetativo (DV), floração e enchimento de grãos (FEG), e maturação (M).

$\mathrm{Na}$ estimativa da variação do armazenamento de água no solo $\left(\Delta \mathrm{A}_{\mathrm{Z}}\right)$, calculou-se a água armazenada no solo diariamente $\left(\mathrm{A}_{\mathrm{Z}}=\theta \mathrm{a} 1000 \mathrm{Z}\right.$, em $\left.\mathrm{mm}\right)$ até a profundidade de $0,40 \mathrm{~m}$ pelo método do trapézio (LIBARDI, 1995). A $\Delta \mathrm{A}_{Z}$ foi obtida pela diferença entre a lâmina de água armazenada no perfil no dia atual e no dia anterior $\left(\Delta \mathrm{A}_{\mathrm{Z}}=\mathrm{A}_{\mathrm{Zi}}-\mathrm{A}_{\mathrm{Zi}-1}\right)$.

A estimativa de ES foi baseada no método do número da curva (SCS-USDA), segundo metodologia apresentada em PANIGRAHI \& PANDA (2003) e PRUSKI et al. (2003).

O fluxo diário de água (q) por meio do limite de $0,40 \mathrm{~m}$ de profundidade foi obtido pela expressão: 


$$
\mathrm{q}=-\mathrm{K}(\theta) \frac{\partial \Psi_{\mathrm{T}}}{\partial \mathrm{Z}}
$$

em que,

$\partial \Psi_{\mathrm{T}} / \partial \mathrm{Z}$ - gradiente hidráulico no solo (m.c.a.) na profundidade de $0,40 \mathrm{~m}$, avaliado por diferenças finitas, por meio dos tensiômetros instalados a 0,30 e $0,50 \mathrm{~m}$ de profundidade.

\section{RESULTADOS E DISCUSSÃO}

\section{Características físico-hídricas do solo}

As características físico-hídricas do solo estão apresentadas na Tabela 1 e correspondem às médias para a camada 0-0,40 m, sendo: ds - a densidade do solo; $\alpha$, m e $\mathrm{n}$ - parâmetros, e $\theta \mathrm{r}$ - umidade volumétrica residual, gerados pelo modelo de GENUCHTEN (1980).

TABELA 1. Características físico-hídricas do solo, para profundidade de $0,40 \mathrm{~m}$.

\begin{tabular}{|c|c|c|c|c|c|c|c|c|c|c|c|c|c|c|}
\hline \multirow{2}{*}{ Área } & $\theta_{0}$ & $\theta_{c c}$ & $\theta_{c}$ & $\theta_{p m p}$ & $d s$ & $K_{0}$ & $\gamma$ & $\alpha$ & $\mathrm{m}$ & $\mathrm{n}$ & $\theta_{\mathrm{r}}$ & Argila & Silte & Areia \\
\hline & & $\left(\mathrm{m}^{3}\right.$ & $\left.\mathrm{m}^{-3}\right)$ & & $\left(\mathrm{kg} \mathrm{m}^{-3}\right.$ & $\left(\mathrm{m} \mathrm{h}^{-1}\right)$ & & & & & $\left(\mathrm{m}^{3} \mathrm{~m}^{-3}\right)$ & & $(\%)$ & \\
\hline $\begin{array}{l}\mathrm{PC} \\
\mathrm{PD}\end{array}$ & 0,47 & 0,40 & 0,35 & 0,28 & 1400 & $\begin{array}{l}0,046 \\
0,115 \\
\end{array}$ & $\begin{array}{l}93,110 \\
90,555\end{array}$ & 0,042188 & 0,192999 & 1,239156 & 0,23 & 66 & 15 & 19 \\
\hline
\end{tabular}

\section{Produtividade de grãos e água recebida pela cultura}

Não houve diferença significativa entre as lâminas aplicadas via irrigação (Tabela 2), para os sistemas de cultivo (PC e PD). Entre os métodos de manejo de irrigação (TENS e TCA), as lâminas médias aplicadas foram significativamente diferentes, sendo que o tratamento TENS recebeu menor quantidade total de água por irrigação $(299,30 \mathrm{~mm})$, o que significou uma economia de $15 \% \mathrm{em}$ relação à lâmina total média de irrigação aplicada no tratamento TCA $(351,82 \mathrm{~mm})$. Os valores de quantidade de água recebida pela cultura, em todos os tratamentos, estão dentro do intervalo especificado por FRIZZONE (1986), que verificou aumento de produtividade de grãos da cultura com lâminas de irrigação aplicadas entre 350 e $530 \mathrm{~mm}$, enquanto QUEIROZ et al. (1996) verificaram maior rentabilidade do feijoeiro irrigado com lâminas entre 400 a $600 \mathrm{~mm}$ durante o ciclo.

Esses resultados são mais relevantes quando confrontados com os de produtividade, uma vez que esses não diferiram significativamente entre os tratamentos de sistemas de cultivo nem entre os de manejo de irrigação, indicando melhor eficiência no uso da água no tratamento TENS. plantio.

Não houve significância estatística para a interação entre manejo de irrigação e sistemas de

TABELA 2. Água recebida pelas plantas (mm) por chuva (P) e irrigação (I) e produtividade de grãos $\left(\mathrm{kg} \mathrm{ha}^{-1}\right)$.

\begin{tabular}{|c|c|c|c|c|c|c|c|c|c|}
\hline \multirow{3}{*}{ Plantio } & \multicolumn{9}{|c|}{ Manejo de Irrigação } \\
\hline & \multicolumn{3}{|c|}{$\mathrm{I}(\mathrm{mm})$} & \multicolumn{3}{|c|}{$\mathrm{P}+\mathrm{I}(\mathrm{mm})$} & \multicolumn{3}{|c|}{ Produtividade $\left(\mathrm{kg} \mathrm{ha}^{-1}\right)$} \\
\hline & TENS & TCA & Média* & TENS & TCA & Média* & TENS & TCA & Média* \\
\hline $\mathrm{PC}$ & 299,96 & 353,71 & $326,84 \mathrm{~A}$ & 461,67 & 515,41 & $488,54 \mathrm{~A}$ & 2397,5 & 2630,6 & $2514,0 \mathrm{~A}$ \\
\hline PD & 298,63 & 349,93 & $324,28 \mathrm{~A}$ & 460,34 & 511,63 & $485,99 \mathrm{~A}$ & 2342,7 & 2471,6 & $2407,2 \mathrm{~A}$ \\
\hline Média* & $299,30 b$ & $351,82 \mathrm{a}$ & & $461,01 b$ & $513,52 a$ & & $2370,1 \mathrm{a}$ & $2551,1 \mathrm{a}$ & \\
\hline C.V. $(\%)$ & & 2,48 & & & 1,66 & & & 16,70 & \\
\hline
\end{tabular}

* Médias seguidas de letras distintas, maiúsculas na vertical e minúsculas na horizontal, diferem entre si, a 5\% de probabilidade, pelo teste de Tukey. 


\section{Variação da umidade do solo}

Verifica-se que nos tratamentos TCA houve maior quantidade de água disponível no solo, resultando em maior reserva de água para as plantas durante o ciclo da cultura, reserva essa que, em nenhum momento, ficou abaixo da RADl (Figuras 2 e 3).

A variação da RADa no TCA foi menor do que no TENS (Tabela 2), tendo sido esse último o tratamento que mais se aproximou do limite superior da RADl, chegando a até ultrapassá-lo no período de 52-58 DAE. Isso não caracterizou a ocorrência de um estresse hídrico severo nas plantas, uma vez que não houve diferença significativa de produtividade entre os tratamentos, caracterizando uma boa disponibilidade hídrica para a planta, tanto para TENS quanto para TCA. Esses resultados são semelhantes aos encontrados por LIBARDI \& SAAD (1994) em trabalho realizado com a cultura do feijoeiro também irrigado via pivô central, cuja produtividade foi de $3.030 \mathrm{~kg} \mathrm{ha}^{-1}$.

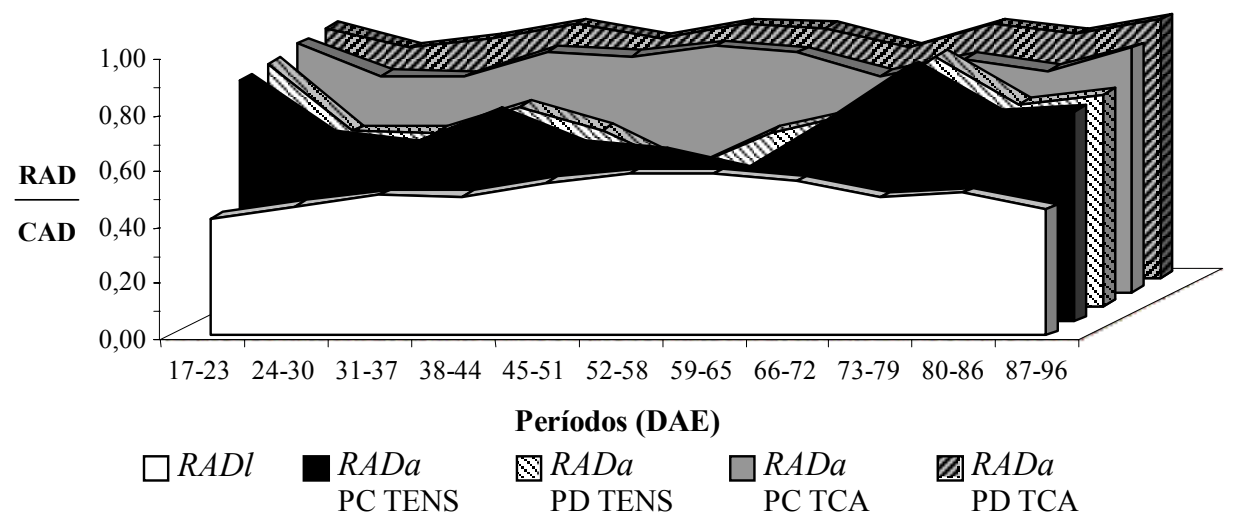

FIGURA 2. Reserva de água disponível limite (RADl) e atual (RADa), como fração da CAD, para todos os tratamentos.

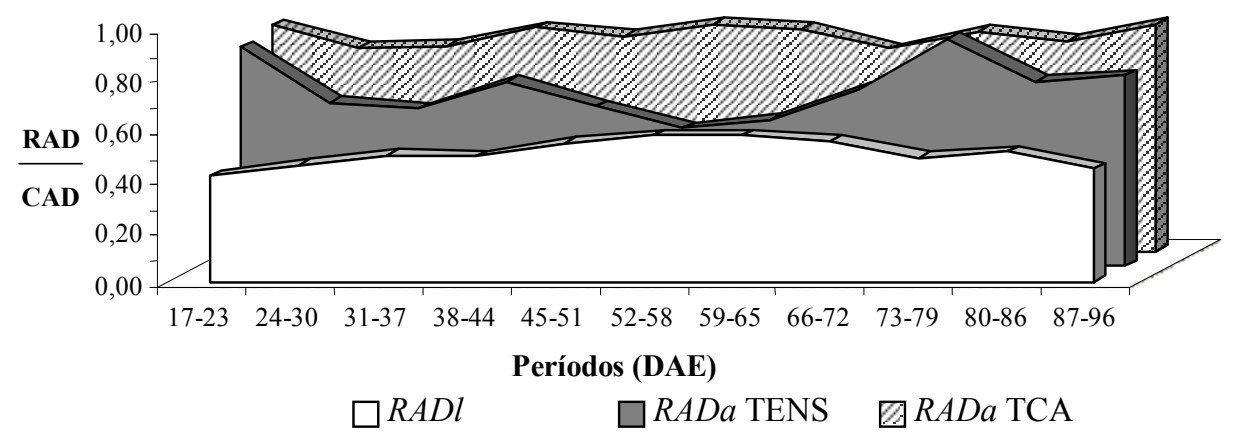

FIGURA 3. Reserva de água disponível limite (RADl) e atual (RADa), como fração da CAD, para os tratamentos TENS e TCA.

\section{Estimativa da ETr pelo método do balanço hídrico no solo}

Por meio dos cálculos realizados para a estimativa da Etr, pode-se verificar a baixa taxa de drenagem interna (q), mesmo nos tratamentos irrigados pelo método TCA, indicando que praticamente não ocorreu percolação de água para as camadas mais profundas. Os valores de q durante todo o ciclo da cultura podem ser considerados insignificantes, uma vez que, em TCA, não ultrapassou 0,3 e 1,2\% do total de água recebida pelas plantas $(\mathrm{P}+\mathrm{I})$ para PC e PD, respectivamente, enquanto, para TENS, esses valores foram de 0,3 e $0,7 \%$. LIBARDI \& SAAD (1994) obtiveram um valor de $q$ não superior a $9,58 \%$ e a consideraram praticamente inexistente. 
Analisando os dados da Tabela 3, verifica-se que os maiores valores de ETr encontrados nos tratamentos irrigados por TCA foram 5,6 e 5,9 $\mathrm{mm} \mathrm{dia}^{-1}$, respectivamente, para PC e PD, enquanto no manejo por TENS foi de $5,1 \mathrm{~mm} \mathrm{dia}{ }^{-1}$ para PC e de 5,0 mm dia ${ }^{-1}$ para PD, ocorrendo esses valores durante o período de floração e enchimento de grãos. Em média, o consumo de água pela cultura foi entre 17 e 96 DAE, cerca de 3,3 $\mathrm{mm} \mathrm{dia}^{-1}$ para os tratamentos irrigados por TENS (PC e PD) e 3,8 e $3,7 \mathrm{~mm} \mathrm{dia}^{-1}$ para PC-TCA e PD-TCA, respectivamente, resultando num consumo total de 263,0 mm (PC-TENS), 302,0 mm (PC-TCA), 259,1 mm (PD-TENS) e 297,9 mm (PD-TCA). Estes resultados de consumo médio diário assemelham-se aos encontrados por OLIVEIRA \& SILVA (1990), em que o maior consumo de água diário pela cultura foi de $5,3 \mathrm{~mm}$ no início da formação de vagens e consumo médio de 3,9 $\mathrm{mm} \mathrm{dia}^{-1}$ de água. ANDRADE et al. (2002) verificaram maior ETr sob plantio direto com valor de $5,93 \mathrm{~mm} \mathrm{dia}^{-1}$ por volta dos 62 DAE.

TABELA 3. ETr $\left(\mathrm{mm} \mathrm{dia}^{-1}\right)$ para a cultura do feijoeiro.

\begin{tabular}{|c|c|c|c|c|c|c|c|c|c|c|c|}
\hline \multirow{3}{*}{ Tratamento } & \multicolumn{11}{|c|}{ Períodos (D.A.E.) } \\
\hline & $17-23$ & $24-30$ & $31-37$ & $38-44$ & $45-51$ & $52-58$ & $59-65$ & $66-72$ & $73-79$ & $80-86$ & $86-96$ \\
\hline & \multicolumn{11}{|c|}{$\operatorname{ETr}\left(\mathrm{mm} \mathrm{dia}^{-1}\right)$} \\
\hline PC-TENS & 1,7 & 3,0 & 3,4 & 1,2 & 4,3 & 4,1 & 4,8 & 5,1 & 3,1 & 2,5 & 3,0 \\
\hline PC-TCA & 1,6 & 3,0 & 3,6 & 2,8 & 4,4 & 5,3 & 5,6 & 5,1 & 3,1 & 4,1 & 3,1 \\
\hline PD-TENS & 2,2 & 3,0 & 1,5 & 3,1 & 4,3 & 3,9 & 5,0 & 4,6 & 3,0 & 2,9 & 2,4 \\
\hline PD-TCA & 1,3 & 2,6 & 3,1 & 3,5 & 4,4 & 5,2 & 5,2 & 5,9 & 2,9 & 3,4 & 3,6 \\
\hline
\end{tabular}

Observa-se que, durante o ciclo da cultura (Figura 4), os tratamentos TENS apresentaram menor ETr do que os irrigados por TCA, sendo que, para esse último, a curva da ETr foi mais próxima à da ETc, evidenciando a diferença de água consumida entre os dois métodos.

Entre as fases fenológicas (Figura 5), os valores médios de ETc e de ETr foram menores na DV, com PC (TENS e TCA) atingindo valores de $\operatorname{ETr}\left(2,7\right.$ e 2,6 $\left.\mathrm{mm} \mathrm{dia}^{-1}\right)$ próximos ao de ETc $\left(2,8 \mathrm{~mm} \mathrm{dia}^{-1}\right)$. Os maiores valores de ETr ocorreram durante a FEG nos tratamentos irrigados por TCA $\left(4,8 \mathrm{~mm} \mathrm{dia}^{-1}\right)$ para uma ETc de $5,2 \mathrm{~mm} \mathrm{dia}^{-1}$. Durante a fase $\mathrm{M}$, esses mesmos tratamentos apresentaram os valores máximos de $\operatorname{ETr}\left(3,8\right.$ para o $P D$ e $3,7 \mathrm{~mm} \mathrm{dia}^{-1}$ para o $\left.P C\right)$, superando o valor de $\operatorname{ETc}\left(3,4 \mathrm{~mm} \mathrm{dia}^{-1}\right)$. 

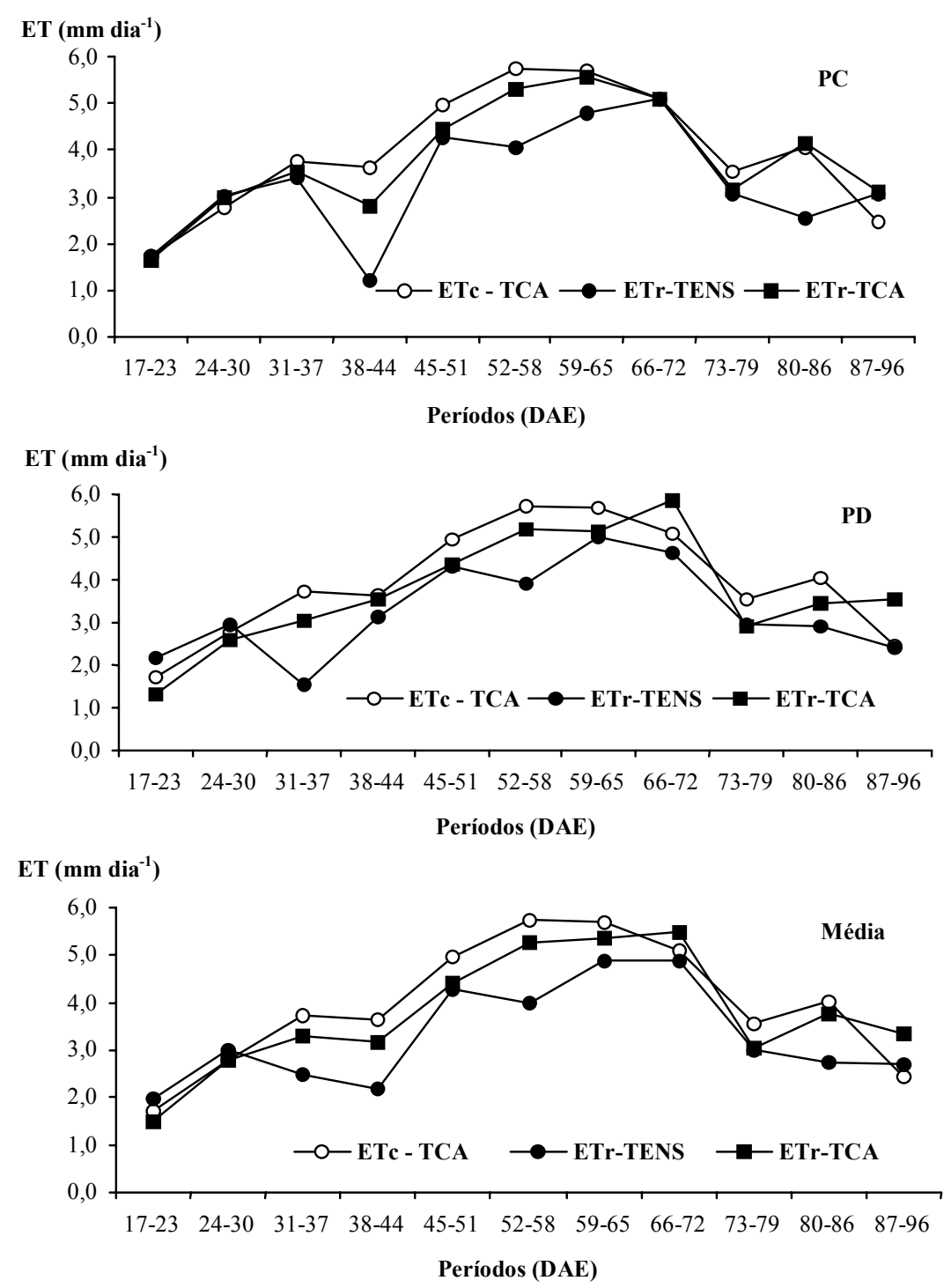

FIGURA 4. ETr estimada pelo método do balanço hídrico no solo e ETc estimada pelo método do TCA (FAO), para PC, PD, TENS e TCA e média para TENS e TCA.

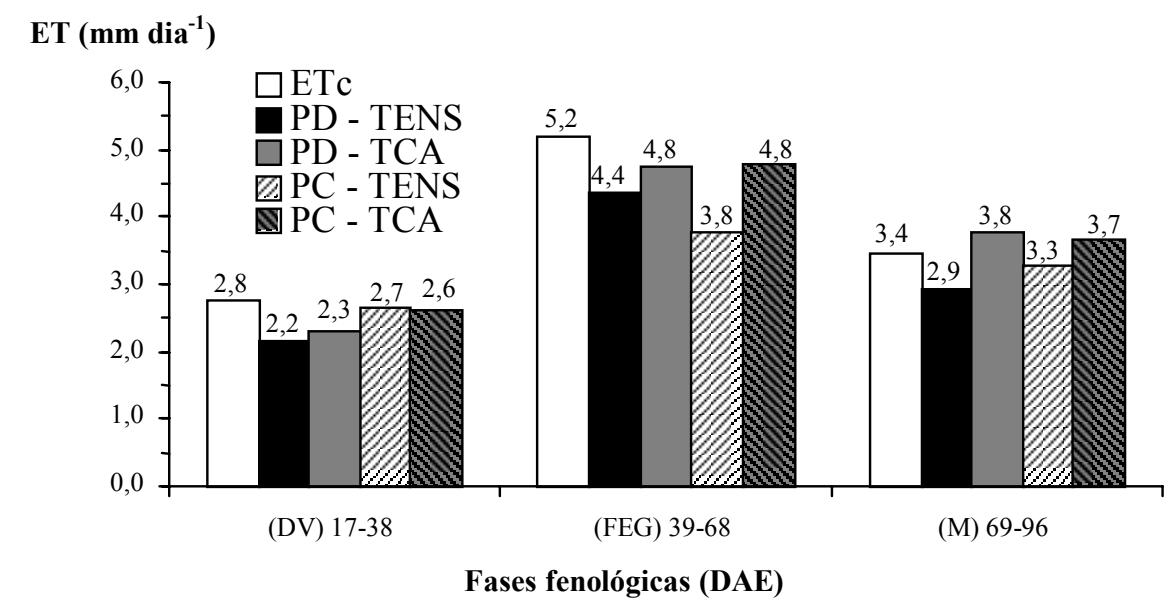

FIGURA 5. ETr estimada pelo método do balanço hídrico no solo e ETc estimada pelo método do TCA, para as fases fenológicas DV, FEG e M. 


\section{CONCLUSÕES}

Ambos os métodos são passíveis de serem adotados por irrigantes ou técnicos extensionistas com nível médio de tecnologia e conhecimento, embora o de tensiometria ofereça, se adequadamente conduzido, melhor entendimento das reais condições hídricas do solo na região do sistema radicular da cultura.

Não foram verificadas diferenças importantes de armazenamento de água no solo e de produtividade de grãos entre os sistemas de plantio nesse primeiro ano.

O manejo por tensiometria resultou em maiores variações na água disponível consumida do solo e em maior eficiência de uso da água de irrigação do que pelo balanço hídrico simplificado com o tanque "Classe A", resultando em economia de $15 \%$ na água de irrigação aplicada, sem afetar a produtividade de grãos.

\section{REFERÊNCIAS BIBLIOGRÁFICAS}

ALLEN, R.G.; PEREIRA, L.S.; RAES, D.; SMITH, M. Pan evaporation method. In: . Crop evapotranspiration. Roma: FAO, 1998a. p.78-85 (Irrigation and Drainage, 56).

ALLEN, R.G.; PEREIRA, L.S.; RAES, D.; SMITH, M. ETc - single crop coefficient (Kc) In: Crop evapotranspiration. Roma: FAO, 1998b. p.103-34 (Irrigation and Drainage, 56).

ALLEN, R.G.; PEREIRA, L.S.; RAES, D.; SMITH, M. ETc under soil water stress conditions. In: . Crop evapotranspiration. Roma: FAO, 1998c. p.161-82 (Irrigation and Drainage, 56).

ANDRADE, R.S.; MOREIRA, J.A.A.; STONE, L.F.; CARVALHO, J.A. Consumo relativo de água do feijoeiro no plantio direto em função da porcentagem de cobertura morta do solo. Revista Brasileira de Engenharia Agrícola e Ambiental, Campina Grande, v.6, n.1, p.35-8, 2002.

EMPRESA BRASILEIRA DE PESQUISA AGROPECUÁRIA - EMBRAPA. Sistema brasileiro de classificação de solos. Rio de Janeiro, Ministério da Agricultura e do Abastecimento, 1999. 412 p.

FRIZZONE, J.A. Funções de resposta do feijoeiro (Phaseolus vulgaris L.) ao uso do nitrogênio e lâmina de irrigação. 1986. 133 f. Tese (Doutorado em Irrigação e Drenagem) - Escola Superior de Agricultura "Luiz de Queiroz", Universidade do Estado de São Paulo, Piracicaba, 1986.

GENUCHTEN, M.Th. van. A closed form equation for predicting the hydraulic conductivity of insaturated soils. Soil Science Society of American Journal, Madison, v.41, p.892-98, 1980.

HERNANDEZ, F.B.T. Manejo da irrigação por pivô central na cultura do milho. In: CONGRESSO BRASILEIRO DE ENGENHARIA AGRÍCOLA, 24., 1994, Viçosa - MG. Anais... Viçosa - MG: Sociedade Brasileira de Engenharia Agrícola, 1994. 13 p. (Artigo 286)

LIBARDI, P. L.; SAAD, A.M. Balanço hídrico em cultura de feijão irrigada por pivô central em latossolo roxo. Revista Brasileira de Ciência do Solo, Campinas, v.18, p.529-32, 1994.

LIBARDI, P.L. Dinâmica da água no solo. Piracicaba: Paulo Leonel Libardi, 1995. 497 p.

OLIVEIRA, F.A.; SILVA, J.J.S. Evapotranspiração, índice de área foliar e desenvolvimento radicular do feijão irrigado. Pesquisa Agropecuária Brasileira, Brasília, v.25, n.3, p.317-22, 1990.

PANIGRAHI, B.; PANDA, S.N. Field test a soil water balance simulation model. Agricultural Water Management, Amsterdam, v.58, p.223-40, 2003.

PEREIRA, L.S.; ALLEN, R.G. Novas aproximações aos coeficientes culturais. Engenharia Agrícola, Jaboticabal, v.16, n.4, p.118-43, 1997. 
PIMENTEL GOMES, F. Curso de estatística experimental. 2. ed. Piracicaba: Universidade de São Paulo - Escola Superior de Agricultura "Luiz de Queiroz", 1963. 384 p.

PIRES, R.C.M.; ARRUDA, F.B.; FUJIWARA, M.; SAKAI, E.; BORTOLETTO, N. Profundidade do sistema radicular das culturas de feijão e de trigo sob pivô central. Bragantia, Campinas, v.50, n.1, p.15362, 1991.

PIRES, R.C.M.; SAKAI, E.; ARRUDA, F.B.; FOLEGATTI, M.V. Necessidades hídricas das culturas e manejo de irrigação In: MIRANDA, J.H.; PIRES, R.C.M. Irrigação. Piracicaba: Sociedade Brasileira de Engenharia Agrícola, 2001. v.1, p.121-04. (Série Engenharia Agrícola)

PRUSKI, F.F.; BRANDÃO, V.S.; SILVA, D.D. Escoamento superficial. Viçosa - MG: UFV, 2003. 88 p. QUEIROZ, J.E.; CALHEIROS, C.B.; PESSOA, P.C.S.; FRIZZONE, J.A. Estratégias ótimas de irrigação do feijoeiro: terra como fator limitante da produção. Pesquisa Agropecuária Brasileira, Brasília, v.31, n.1, p.55-61, 1996.

SAAD, A.M.; LIBARDI, P.L. Uso prático do tensiômetro pelo agricultor irrigante. São Paulo: IPT, 1992. 27 p.

SILVEIRA, P.M.; STONE, L.F. Manejo da irrigação do feijoeiro: uso do tensiômetro e avaliação do desempenho do pivô central. Goiânia: EMBRAPA, 1994. 46 p. (Circular Técnica, 27).

STONE, L.F.; MOREIRA, J.A.A. Efeitos de preparo do solo no uso da água e na produtividade do feijoeiro. Pesquisa Agropecuária Brasileira, Brasília, v.35, n.4, p.835-41, 2000.

STONE, L.F.; MOREIRA, J.A.A. Resposta do feijoeiro ao nitrogênio em cobertura sob diferentes lâminas de irrigação e preparos do solo. Pesquisa Agropecuária Brasileira, Brasília, v.36, n.3, p.473-81, 2001.

WUTKE, E.B.; ARRUDA, F.B.; FANCELLI, A.L.; PEREIRA, J.C.V.N.A.; SAKAI, E.; FUJIWARA, M.; AMBROSANO, G.M.B. Propriedades do solo e sistema radicular do feijoeiro irrigado em rotação de culturas. Revista Brasileira de Ciência do Solo, Viçosa, v.24, n.3, p.621-33, 2000. 